\title{
Revival of Kasuti Embroidery Motifs as Hand Painting
}

\author{
Renu, Nisha Arya, Neha Chauhan* and Suman Sodhi \\ Department of Textile and Apparel Designing, I.C. College of Home Science, CCSHAU, \\ Hisar, Haryana, India \\ *Corresponding author
}

\section{Key w o r ds \\ Kasuti, Embroidery, Technique, Motifs, Placements \\ Article Info \\ Accepted: \\ 04 October 2018 \\ Available Online: \\ 10 November 2018}

\section{A B S T R A C T}

India has always been known as the land that portrays culture and traditional vibrancy through its conventional art and craft. Embroidery is said to be the oldest and beautiful way of surface enhancement. Though, the revival of traditional kasuti embroidery needs to be paired with ways to find new and modern-day expression in harmony with the needs and ends of future citizens of the world, despite the fact valuing the tradition. There is also a need to enhance understanding and to provide necessary support for professional marketing and adaptation to global demands as the craft moves into the new era. The study on revolution of kasuti embroidery motifs as hand painted articles was conducted for exploring the possibility to enhance creativity by adapting traditional kasuti embroidery motifs for hand painting. Total fifteen motifs from three categories i.e. geometrical, floral and animal and bird were selected and converted into forty-five designs. Top three designs were selected each for file folder for further application using hand painting technique. Developed articles were highly acceptable by respondents in terms of created designs, design placements, overall appearance, colour ways, technique and cost. Respondents had high opinion about developed articles. It was found that transformation of innovative designs of kasuti embroidery into hand painting has enhanced the range of designing and productivity. Variability of designs was created through the use of CAD technology using design tools which aided creativity and made the process more efficient.

\section{Introduction}

India is a land of rich culture and diverse traditions. India has always been known as the land that represents culture and traditional vibrancy through its conventional art and craft. Indian arts and crafts comprehend various forms such as painting, pottery, home decorations, cloth making, needle crafts, jewellery and so on with delicate designs and patterns. Its long-known heritage of art, music, dance, sculpture, architecture, carpentry, metal work, designing, painting and embroidery exemplifies the richness of Indian culture (Pandit, 1976).

Every region in India has its individual style and pattern of art known as folk art. The folk and tribal arts of India are very ethnic and simple and yet colourful and vibrant enough to express volumes about the country's rich heritage. Indian arts and crafts have the great potential in the international market because of its traditional aesthetic sensibility and 
authenticity (Sharma, 2015). These crafts are not solitary used for decorating and religious purposes but they also outfit to day-to-day needs of the people. Printing, painting, dyeing, brocading techniques are some of the techniques that have been traditionally used all over the world to decorate textiles, apparels and home furnishing articles for their personal use. Among these, Indian embroidery greatly expresses the richness of diversity because the art of embroidery is exhibited by Indians who have been living widely region wise India has a rich heritage of embroideries and people are well versed with traditional embroidery designs. Each state in India is unique in itself as far as embroidery of its variegated designs is concerned (Namrata and Nack, 2008). Almost every region of India has a distinct style of embroidery based on cultural history of the region (Bennur and Gavai, 2015). Each state in India is unique in itself as far as embroidery of its variegated designs is concerned (Namrata, 2006).

Kasutiis world famous embroidery of Karnataka state and is renowned in many places of Bijapur, Dharwad, Belgaum and Jamakhandi districts. Its subtle rendition is a result of the honest, zealous and innate desire of "mankind" to practice the beautiful stitches on the articles of everyday use. The motifs used in Kasuti embroidery extended from mythological and architectural to beautiful flora and fauna, i.e. gopuras, chariot, shivalinga, bull (Nandi), tiger, lamp stand, crown of Shiva (ShivanaBasinga), swastika, sun, suryamukhi, asanas, Rama"es cradle, snake (Naga devta), elephant, horse, Hanuman etc. The key speciality of this embroidery is that the design is never traced on the material to be embroidered and the embroidery starts without knotting thread but with a tiny back stitch. The stitches are simple, minute, intricate and beautiful. Kasuti is always done by counting the threads. The four types of stitches are Gavanti (a double running stitch), "Negi" (a simple running stitch), "Murgi" (a zig-zag stitch) and a cross stitch- menthe (Pandit, 1976)

Due to modernization and ever changing fashion scenario, demands for new textile designs are growing day by day (Rai, 2002). Textile designing is hence emerging as a field full of scope and creativity. Hence, for firming this sector product diversification and creating market demand is extremely essential. Fabric painting can produce embroidery like effect on any fabric with the right fabric paint and applicators. Fabric painting gives magnificent surface decoration in lesser time as compared to embroidery. Today, the usage of fabric painting has revolutionized to such an extent that it is a popular homemade handcraft. It is the lively expression of fabrics. Fabric painting can be carved at a very affordable price with simple techniques and procedures (Devi et al., 2017).

In an era of time strain, there is a necessity to explore the possibility of transformation of embroidery designs for fabric painting. The people engaged in the activity of fabric embellishment, will find fabric painting as more convenient and less time-consuming resulting in more earning. Use of traditional embroidery designs for transformation into fabric painting will help in the revival of traditional embroidery and give it a new look as per trend. Keeping these facts in mind a study with the objective of creating designs from selected motifs of Kasuti embroidery for fabric painting was conducted.

\section{Materials and Methods}

\section{Technical plan}

The methods, techniques, tools and procedures adopted for the present investigation have been categorised under following steps to achieve the planned objectives. 


\section{Collection of motifs}

Motifs of kasuti embroidery were collected from secondary sources like books, magazines, journals and internet. A total of fifty motifs were collected. The collected motifs were categorized in three categories as geometrical, floral, and animal and bird motifs. The categorized motifs were screened into thirty motifs by advisory committee keeping in mind their suitability for fabric painting on selected articles. These three categories included ten motifs each. Thus, a total of thirty motifs were finalized for further research work.

The selected motifs were scanned to convert them from print version to digital format and edited with the help of CorelDraw software. The proportion of motifs was changed to make them suitable for hand painting on textile articles.

\section{Selection of motifs}

Thirty motifs were got assessed by experts with the help of developed preferential index. The experts were asked to give their preferences for each motif separately in different categories for its suitability to hand painting. Their preferences were taken on three-point continuum scale as most preferred, preferred and least preferred. The weighted mean score of each motif was calculated to give ranks in different categories. A total of fifteen motifs including five top ranked motifs from each category i.e. geometrical, floral and animal \& bird motifs were selected to create designs.

\section{Selection of article}

For selection of article to be developed for application of adapted motifs of kasuti embroidery through hand painting technique, a list of textile articles under three broad heads i.e. apparel, accessories and utility articles and home textiles was prepared and sorted with the help of advisory committee members. The articles were selected on the basis of their weighted mean score according to expert's choices. The most preferred article i.e. file folder was selected for product development and application of kasuti embroidery motifs through hand painting technique.

\section{Creation and selection of designs}

Fifteen selected motifs i.e. five top ranked motifs from each category were used to develop designs. Designs were created on the basis of their suitability for fabric painting on file folder with the help of CorelDraw using graph of $2.0 \mathrm{~mm}$ size. Each motif was converted into three designs. Hence, a total of forty-five designs were created. The created designs were got assessed by experts and three top ranked designs were each selected for preparation of design placements on file folder.

\section{Preparation of design placements and their selection}

Three top ranked designs each were used to prepare design placements on file folder. Three placements of each design were made on the article with the help of Corel DRAW. These placements were got assessed by the experts and top ranked placement of each design was selected for hand painting.

\section{Assessment of developed articles}

Consumer acceptability of the developed hand painted file folder were assessed using selfstructured evaluation Performa.

\section{Results and Discussion}

Kasuti embroidery motifs were collected, screened and categorized as geometrical, floral 
and animal and bird motifs, including ten motifs each. Top ranked five motifs in each category were selected by experts for further research work. A total of forty-five designs were created using fifteen selected motifs, with the help of CorelDraw software. Top ranked three designs were selected for file folder by experts, using a preferential choice index.

Preferences of experts for design placements on selected articles

Three placements of each selected design were made on front, back of file folder. A total of nine placements were prepared and assessed by experts. The nine placements i.e. three of each selected design are presented in plate I.

Preferences of experts for design placements on file folder

The data envisaged that highly preferred placement of design number 21 was placement II which got It $^{\text {st }}$ rank with 2.35 WMS. Placement I of design number 21 was preferred placement and got II ${ }^{\text {nd }}$ rank with 2.3 WMS followed by placement III with 1.55 WMS and got III $^{\text {rd }}$ rank. Highly preferred placement of design number 28 was placement I which got $\mathrm{I}^{\text {st }}$ rank with 2.65 WMS. Placement III of design number 28 was preferred placement and got II $^{\text {nd }}$ rank with 2.4 WMS followed by placement II with 1.95 WMS and got III ${ }^{\text {rd }}$ rank. Placement I of design number 37 was highly preferred with 2.5
WMS and got $\mathrm{I}^{\text {st }}$ rank. Placement II of design number 37 was preferred placement and got II $^{\text {nd }}$ rank with 2.4 WMS followed by placement III with 1.8 WMS and got III $^{\text {rd }}$ rank. Top ranked placement of each design was selected for application on file folder (Table 1).

Thus, placement I of design number 28, 37 and placement II of design number 21 were top ranked and highly preferred placements. These were selected for application on file folder.

Assessment of developed articles for consumer acceptability on various parameters

The developed articles were assessed by sixty consumers for their acceptability level on various parameters. The data pertaining to acceptability of painted file folder depicted that design number 37 was assessed as highly acceptable and design 28 was assessed as acceptable by consumers on all the four parameters i.e. design placement (2.4), color way (2.36), technique (2.33) and created design (2.3) of design number 37 and design placement (2.5), created design (2.46), colour way (2.16) and technique (2.1) of design number 28. Design number 21 of painted file folder was assessed acceptable for created design (2.43), design placement (2.2), technique (2.06) and colour way (2.0) (Table 2).

Table.1 Preferences of experts for design placements on file folder $n=20$

\begin{tabular}{|c|c|c|c|c|c|c|}
\hline \multirow{2}{*}{$\begin{array}{c}\text { Design } \\
\text { number }\end{array}$} & \multicolumn{2}{|c|}{ Placement I } & \multicolumn{2}{c|}{ Placement II } & \multicolumn{2}{c|}{ Placement III } \\
\hline & $\begin{array}{c}\text { WMS } \\
(\mathbf{n = 2 0})\end{array}$ & Rank & $\begin{array}{c}\text { WMS } \\
(\mathbf{n = 2 0})\end{array}$ & Rank & $\begin{array}{c}\text { WMS } \\
(\mathbf{n = 2 0})\end{array}$ & Rank \\
\hline 21 & 2.3 & II & 2.35 & I & 1.55 & III \\
\hline 28 & 2.65 & I & 1.95 & III & 2.4 & II \\
\hline 37 & 2.5 & I & 2.4 & II & 1.8 & III \\
\hline
\end{tabular}

WMS-Weighted Mean Score, Highly Preferred 2.34-3.00, Preferred 1.67-2.33, Least Preferred 1.00-1.66 
Table.2 Assessment of developed articles for consumers acceptability on various parameters

$(n=60)$

\section{File folder}

\begin{tabular}{|l|c|c|c|c|c|}
\hline Painted fille folder (21) & 2.43 & 2.2 & 2.0 & 2.06 & $2 . .17$ \\
\hline Painted file folder (28) & 2.46 & 2.5 & 2.16 & 2.1 & 2.30 \\
\hline Painted file folder (37) & 2.3 & 2.4 & 2.36 & 2.33 & 2.34 \\
\hline Average Score & 2.39 & 2.36 & 2.17 & 2.16 & 2.27
\end{tabular}

WMS-Weighted Mean Score, Highly acceptable 2.34-3.00, Acceptable 1.67-2.33, Least acceptable 1.00-1.66

Table.3 Assessment of developed articles as per overall appearance $(n=60)$

\section{File folder}

Painted file folder (21)

Painted file folder (28)

Painted file folder (37)

\begin{tabular}{|c|c|}
\hline 2.3 & III \\
\hline 2.46 & II \\
\hline $\mathbf{2 . 6 3}$ & I \\
\hline
\end{tabular}

WMS-Weighted Mean Score, highly appealing 2.34-3.00, Appealing 1.67-2.33, Least appealing 1.00-1.66

Table.4 Opinion of the consumers regarding adaptation of kasuti embroidery motifs for hand painted $n=60$

\begin{tabular}{|l|l|c|c|}
$\begin{array}{l}\text { Sr. } \\
\text { No }\end{array}$ & Opinion statements & \multicolumn{2}{|c|}{$\begin{array}{c}\text { Painted } \\
\text { articles }\end{array}$} \\
\hline 1 & Selected technique is easy in execution. & 2.53 & III \\
\hline 2 & $\begin{array}{l}\text { Effect of kasuti embroidery can be effectively replicated } \\
\text { with fabric painting. }\end{array}$ & 2.63 & II \\
\hline 3 & $\begin{array}{l}\text { Fabric painting is time saving and cost effective, surface } \\
\text { embellishment technique. }\end{array}$ & 2.43 & V \\
\hline 4 & Fabric painting maintains the beauty of kasuti embroidery. & 2.70 & I \\
\hline 5 & Fabric painting is as per latest consumer's demand. & 2.50 & IV \\
\hline
\end{tabular}

WMS-Weighted Mean Score, High Opinion 2.34-3.00, Medium Opinion 1.67-2.33, low Opinion 1.00-1.66

\section{Selected designs for hand painting on file folder}

\begin{tabular}{|c|c|c|}
\hline & \\
\hline
\end{tabular}




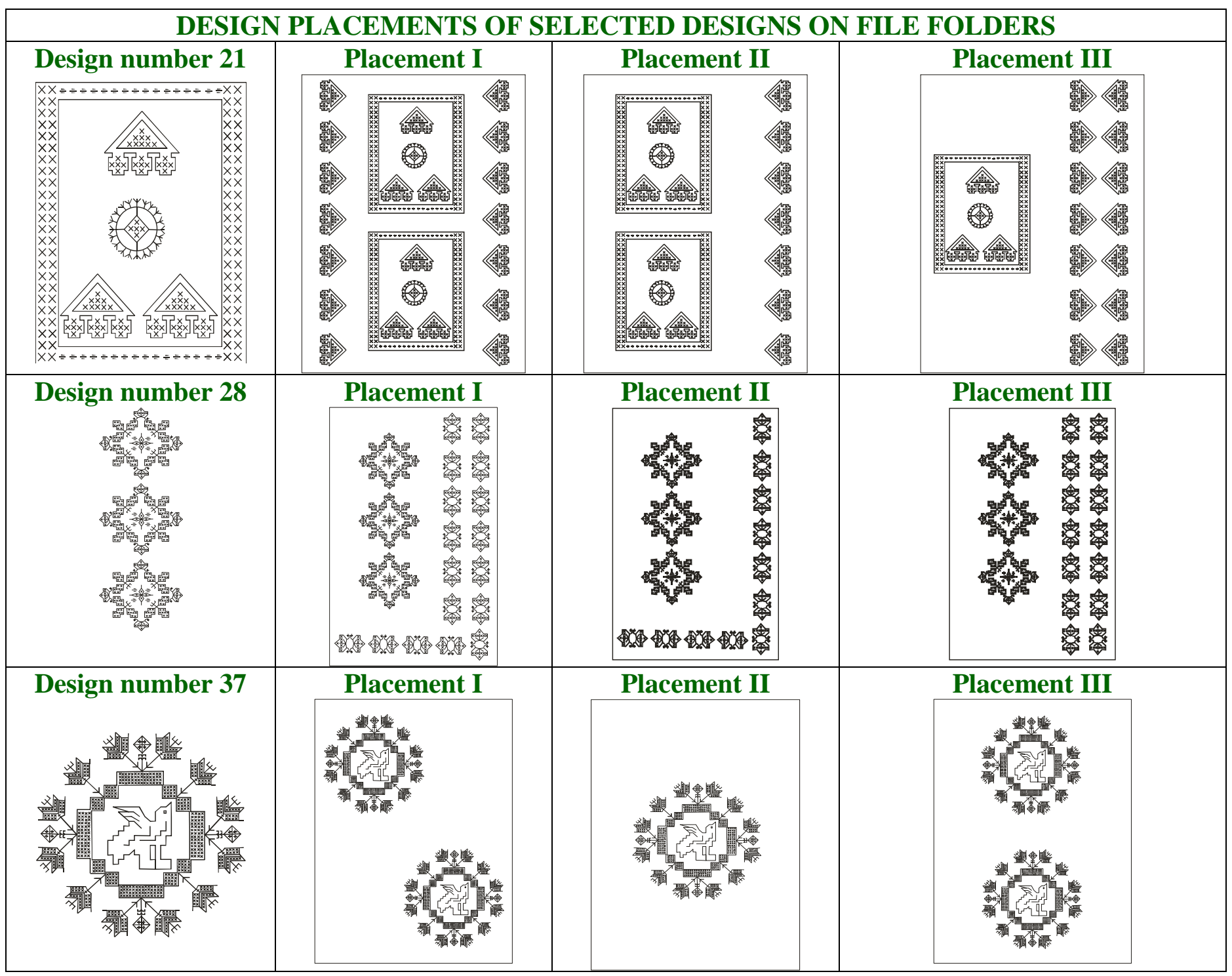

Developed file folder with hand painting technique

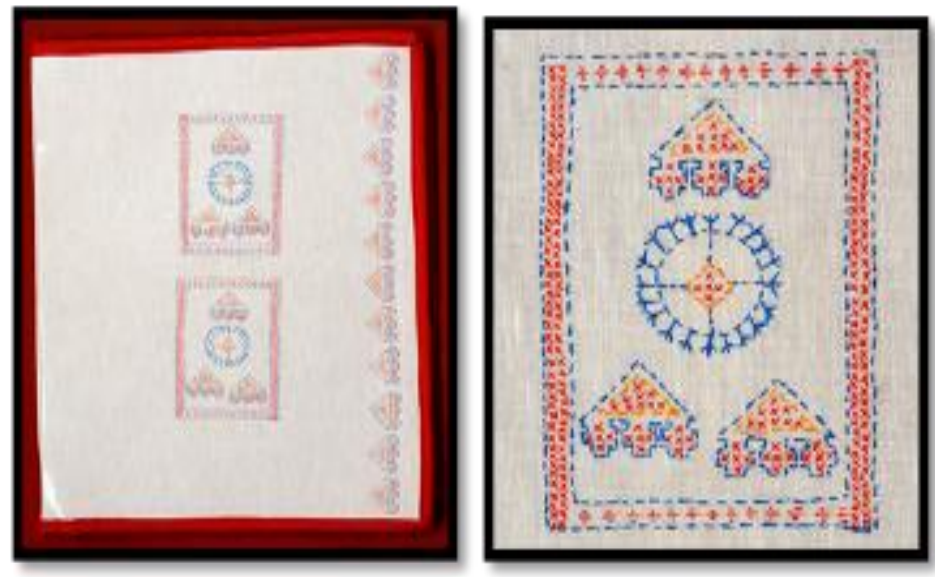

Design number. 21 

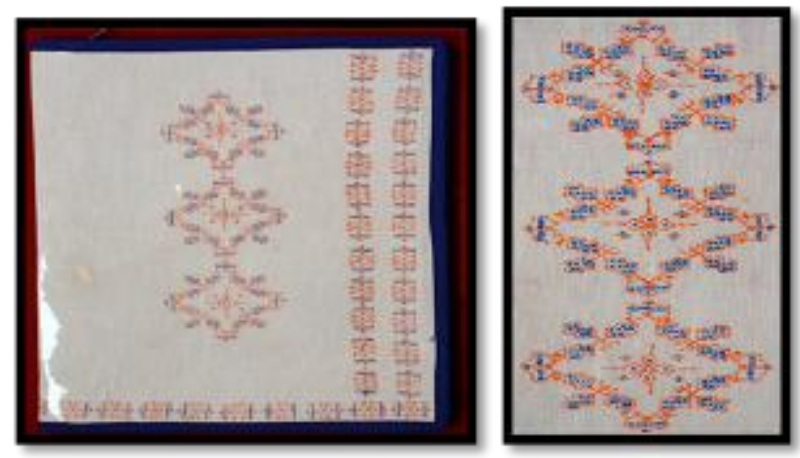

Design number. 28

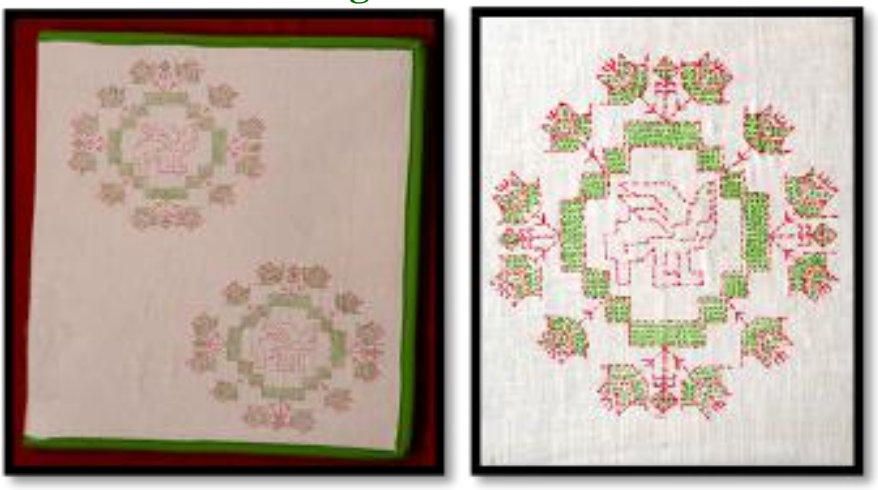

Design number. 37

Assessment of developed articles as per overall appearance

The data presented, elucidated that Painted file folder of design number 37 got $\mathrm{I}^{\text {st }}$ rank with 2.63 score. Painted file folder of design

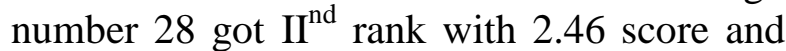
painted file folder of design number 21 got III $^{\text {rd }}$ rank with 2.30 score. Thus, it is inferred that in terms of overall appearance, all the jackets \& file folder were assessed as highly appealing except one file folder as appealing (Table 3).

Opinion of the consumers regarding adaptation of kasuti embroidery motifs for hand painting

It is apparent from data in table 4 that foremost opinion of consumers regarding adaptation of kasuti embroidery for fabric painting was that 'fabric painting maintains the beauty of kasuti embroidery' with 2.70 WMS got $I^{\text {st }}$ rank, followed by the opinion that 'effect kasuti embroidery can be effectively replicated with fabric painting' with 2.63 WMS got II $^{\text {nd }}$ rank, 'selected technique is easy in execution with 2.53 WMS got III ${ }^{\text {rd }}$ rank, 'selected technique is as per latest consumer's demand with 2.5 WMS got IV $^{\text {th }}$ rank and 'fabric painting is time saving and cost effective surface embellishment technique' with 2.43 WMS got $\mathrm{V}^{\text {th }}$ rank. Thus, consumers had high opinion regarding adaptation of kasuti embroidery for hand painting as they strongly opined that hand painting is time saving and costeffective surface embellishment technique as per latest consumer's demand. It was easy in execution and has effectively replicated the effect of kasuti embroidery to maintain its beauty with WMS ranging between 2.43 to 2.70 (Table 4).

\section{Recommendations}

Developed kasuti embroidery hand painted designs can be used for variety of textile, 
apparel and household articles. The findings of this research can be disseminated to the persons who are working towards revival of traditional embroideries. This activity can be taken up by women entrepreneurs to start a small-scale business as fabric painting is an innovative, economical and time saving surface embellishment technique.

Adaptation of traditional kasuti embroidery motifs for hand painting enhanced the prospect of creativity. Transformation of innovative designs of kasuti embroidery into hand painting has enhanced the array of designing and productivity. Developed articles were highly acceptable by respondents in terms of created designs, design placements, colour ways, technique, overall appearance and cost. Respondents had high opinion about developed articles. Variation of designs can be created through the use of CAD technology employing design tools which aid creativity and make the process more efficient.

\section{References}

Asihene, E. 2004. A Brief History of Art. Woeli Publishing Services. Accra. Pp. 56-58.

Bennur, S. and Gavai, L. 2015. Regional traditional Indian embroidery "Kasuti" key success factors to reach the international markets. Journal of Textile Science \& Engineering. 5: 3.

Chaudhary, B. A. and Pant, S. 2014. Animal and birds as design ornamentation in traditional Indian embroideries. Golden Research Thoughts. 9(3): 7-9.

Devi (2011) Devi, S. 2011. Adaptation of traditional embroidery designs for fabric painting on jacket. Master's Thesis, CCS Haryana Agricultural University, Hisar, India.

Devi, S., Punia, P., Pruthi, N. and Sisodia, N. 2017. Transformation of kantha traditional embroidery: as fabric painting. Indian Journal of Traditional Knowledge 16(4): 720-725.

Gulia, B.S. 2008. The Traditions of North India. A study on art, architecture and crafts in Haryana, Shubhi Publications, Gurgaon, India. Pp: 24-25.

Kaur, A. 2015. Embroidery- An embellishment on women's wear. Research Journal of Family, Community and Consumer Sciences. 3(9): 4-6.

Kavita. 2016. Adaptation of canvas embroidery motifs for fabric painting. Master's Thesis. CCS Haryana Agricultural University, Hisar, India.

Naik, S. D. and Vastrad, V. J. 2008. Protection and revival of traditional hand embroidery, Kasutiby Automation. Indian Journal of Traditional Knowledge. 7(1): 197-203.

Pandit, S. 1976. Indian Embroidery- Its variegated charms. Jaymudra, Laxmi Estate, Bahuchargi Road, Baroda: 1820.

Rai, I. 2002. Problems and prospects in the 21st century. Books treasure, Jodhpur. Pp: 132-133.

\section{How to cite this article:}

Renu, Nisha Arya, Neha Chauhan and Suman Sodhi. 2018. Revival of Kasuti Embroidery Motifs as Hand Painting. Int.J.Curr.Microbiol.App.Sci. 7(11): 3409-3416. doi: https://doi.org/10.20546/ijcmas.2018.711.391 